\title{
VOLUMETRIC COMPARISONS OF BRAIN STRUCTURES IN BATS (AN ATTEMPT AT A PHYLOGENETIC INTERPRETATION)
}

\author{
by
}

\author{
HEINZ STEPHAN \& PAUL PIRLOT \\ Max-Planck-Institut für Hirnforschung, Frankfurt a.M. - Niederrad, B.R. Deutschland and Faculté \\ des Sciences de l'Université de Montréal, Départment de Biologie, Montréal, P.Q., Canada
}

Bats show, in spite of the unity which they derive from the unique possession of flight-ability, remarkable differences in their encephalization (Pirlot \& Stephan, 1970). These differences were found to be more closely related to feeding habits than to systematic relationships. The brains of the insect hunting species show the lowest degree of encephalization when treated with the allometry formula. Then, in ascending order, come the nectarfeeders, the frugivorous Microchiroptera, the fisheaters, the vampires and finally the frugivorous Megachiroptera.

The present analysis of a variety of parts of the brain confirm the close relationships between characteristics of the brain and feeding habits. Therefore, in spite of the relatively restricted material, an attempt was made to interpret this surprising interdependence, its possible causes and ways of phylogenetic development.

\section{MATERIAL AND METHODS}

The investigation was conducted on 20 brains from 18 species belonging to 8 families, as follows: Noctilionidae: Noctilio leporinus

Rhinolophidae: Rhinolophus hipposideros

Hipposideridae: Hipposideros bicolor, Asellia tridens

Phyllostomatidae: Phyllostomus discolor, Glossophaga soricina, Carollia perspicillata, Sturnira lilium, Vampyrops helleri, Artibeus jamaicensis, $A$. lituratus

Desmodontidae: Desmodus rotundus

Vespertilionidae: Myotis nattereri, $M$. myotis

Molossidae: Chaerophon leucostigma

Pteropidae: Cynopterus brachyotis, $C$. horsfieldii, Eonycteris spelaea
The brains were embedded in paraffin and sectioned serially. The $10 \mu$ sections were alternately stained with cresyl-violet for nerve-cells, and by the Heidenhain-Woelcke technique for myelinated fibers.

Methods for estimating and comparing the size of the brains and its parts have been described in previous publications (Stephan, 1967; Pirlot \& Stephan, 1970). To facilitate the understanding of the quantitative results, we would like, however, briefly to repeat here the main points of those methods: (1) Volume estimation from enlarged photographs of serial sections at equal intervals. (2) Comparison of the absolute values with the aid of the allometry formula, i.e. taking into account the differences in body size (fig. 1). (3) Reference to the size of the corresponding structures in the "basal insectivores", which are the most primitive living placentals according to characteristics of the brain (fig. 1). (4) Introduction of "Progression Indices" which allow a direct numerical estimate of how many times a given brain structure of a certain species is larger than the corresponding structure in a typical basal Insectivore of the same body-weight (fig. 2). The progression indices are indicative values, which, although not precise, are certainly sufficient for the type of comparison made here. (5) Arrangement of the various progression indices in scales and comparisons (figs. 2-4).

The following parts of the brain were studied: bulbus olfactorius, palaeocortex + amygdaloid complex, septum, striatum, schizocortex (= regio entorhinalis + praesubicularis), hippocampus, neocortex, diencephalon, mesencephalon, cerebellum and medulla oblongata. 


\section{RESULTS AND CONCLUSIONS}

The most progressive structure in bats is the neocortex (on the average 3.8 times larger than in basal Insectivores). In a descending sequence (fig. 3 ) follow the cerebellum (2.9), mesencephalon, diencephalon and striatum (2.3-2.2), schizocortex (1.9), hippocampus (1.6), medulla oblongata (1.5) and septum (1.4). The palaeocortex (0.8) and in particular the olfactory bulb (0.6) show, on the average, a regression or decrease in comparison with the basal insectivores (fig. 3).

These average values can only give a general indication of the trends and intensities of size modifications. The separate values for the various species can vary in a wide range (e.g. from 1.6 to 4.0 in the cerebellum and from 0.2 to 1.1 in the olfactory bulb). The difference in size (expressed by the degree of progression) can partly be re-

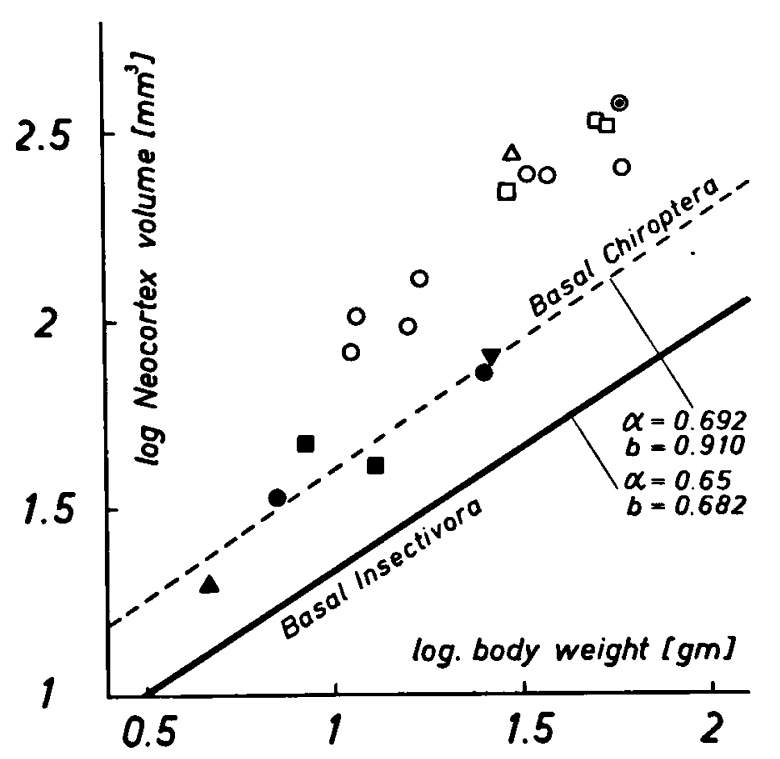

$\begin{array}{llll}\text { Noctilionidae } & \Delta & \text { Desmodontidae } \\ \text { Rhinolophidae } & \text { Vespertilionidae } \\ \text { Hipposideridae } & \nabla & \text { Molossidae } \\ \text { O Phyllostomatidae } & \text { D } & \text { Pteropidae }\end{array}$

Fig. 1. Volumes of the neocortex in relation to body weight on a double logarithmic scale. The base of reference is the line through the point of the mean values for the basal Insectivores with the most probable gradient for the neocortex, which comes close to 0.65 . This value was obtained through the comparison of as many related groups as possible in all material so far investigated (Insectivora, Primates, Chiroptera). It is the expression of the most typical size-relation between volume of the neocortex and body weight. $\alpha=$ slope of the line, $b=$ point of intersection with the ordinate.

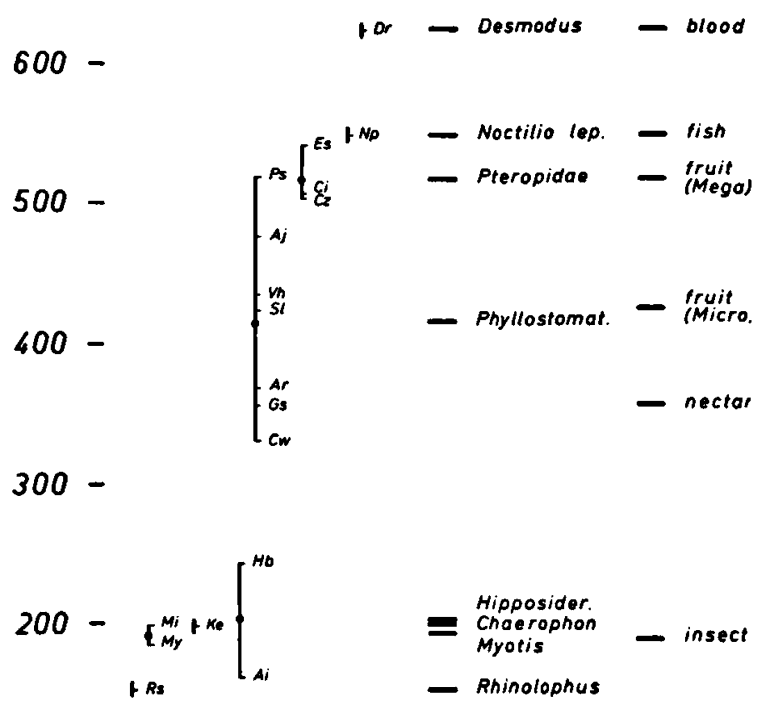

Fig. 2. Progression indices of the neocortex. They express how many times the neocortex is larger than that of a typical basal Insectivore of equal body weight. On the left side (vertical columns) the different species and their range of variation within each family with the mean value of the indices shown by a dot. The family mean points are arranged in an ascending pattern from left to right. In the middle, the horizontal bars correspond to these means and the name of each family is given. On the right hand side the horizontal bars correspond to the means of the various dietary groups. The affiliation of the various species to the dietary groups is as follows :

Insect-eaters - Ai Asellia tridens, Hb Hipposideros bicolor, Ke Chaerophon leucostigma, Mi Myotis nattereri, My Myotis myotis, Rs Rhinolophus hipposideros.

Nectar-feeder - Gs Glossophaga soricina.

Frugivorous Microchiroptera - Aj Artibeus jamaicensis, Ar Artibeus lituratus, Cw Carollia perspicillata, Ps Phyllostomus discolor, Sl Sturnira lilium, Vh Vampyrops helleri.

Frugivorous Megachiroptera - Ci Cynopterus horsfieldii, $\mathrm{Cz}$ Cynopterus brachyotis, Es Eonycteris spelaea.

Fish-eater - Np Noctilio leporinus.

Blood-sucker - Dr Desmodus rotundus.

lated to functional characteristics and/or different feeding habits (fig. 4). The ol f a c t o r y bul b shows a clear although varied decrease in all groups except in the frugivorous Megachiroptera. According to our comparisons, olfaction is least important in the insect- and fish-eaters, and highest in the fruit eating bats, especially in the pteropids. This fits well with behavioural observations made by various authors. The 1 i m bi c struct u r e s (septum, hippocampus and schizocortex) are better developed in vegetarian types than in bats with an animal diet. The size of $\mathrm{medu} 11 \mathrm{a}$ oblongat a and mesencephal o neems to be in relationship to ultra-sonic echolocation. 


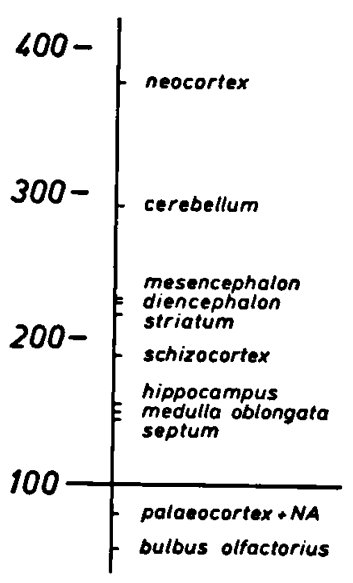

Fig. 3. Average progression indices of the measured brain structures in the 18 Chiroptera-species so far investigated. For base of reference see fig. 4.

These centers are especially large in the fisheating Noctilio leporinus. The ce re be $\mathrm{llum}$ as the center for movement coordination, muscular tonus and body balance is highly developed in all Chiroptera. Surprisingly, in the nimble insecthunters the cerebellum appears to have its least progression. In such relatively poor fliers as the pteropids it is even slightly more progressive (fig. 4). The highest progression is found in the vampire (Desmodus rotundus). We believe that a broadening of the locomotion spectrum (e.g. climbing habits or finely adjusted approach to the skin of large blood-dispending prey) is reflected in cerebellar size. Corresponding results can be deduced also for birds from the work of Portmann (1947).

The size of the preceding structures seems to be independent of that of the neocortex, whereas that of the diencephalon and striatum is more closely related to it. The neocortex includes the highest centers of integration and its size therefore is used to evaluate the evolutionary level reached by each species. The scale of increasing neocorticalization (fig. 2) is interpreted as an "Ascending Chiroptera-Scale". At the bottom of this scale we find representatives of the rininolophids, vespertilionids, molossids and hipposiderids. In these families, the neocortex is between 1.5 and 2.5 times larger than in basal Insectivores of equal body size. They make a comparatively well defined inferior group, separated from all others (figs. 1 and 2). We call them "Basal Chiroptera" (they occupy the basal place within the recent forms) and all of them are insect-eaters. They are followed in the ascending scale (fig. 2) by the nectarivorous and frugivorous phyllostomatids, the neocortex of which is on the average 4 times larger than that of basal insectivores. The slower and heavy flying Megachiroptera overlap slightly with the upper portion of the phyllostomatid range, having a neocortex more than 5 times larger than that of basal insectivores. They are surpassed only by the fisheating Noctilio leporinus (Noctilionidae) (5.5) and the blood-sucking Desmodus rotundus (Desmodontidae) (6.2).

The scale of increasing neocorticalization (= ascending Chiroptera-Scale, fig. 2) represents of course no direct sequence of evolutionary stages in the sense that the more progressive forms have passed through all the individual lower stages.

How then, can the ascending scale contribute to the problems of phylogenesis? We think it can, under the following assumptions: (1) It seems possible and likely, that the lowest recent forms under consideration correspond well with phylthe sense that the more progressive forms have passed during phylogenesis. (2) It is improbable that the development of higher nerve centers reverts under normal wild life conditions (in contrast to domestication and captivity). The size of the neocortex is therefore considered an effective guide in the discussion of phylogenetic sequences.

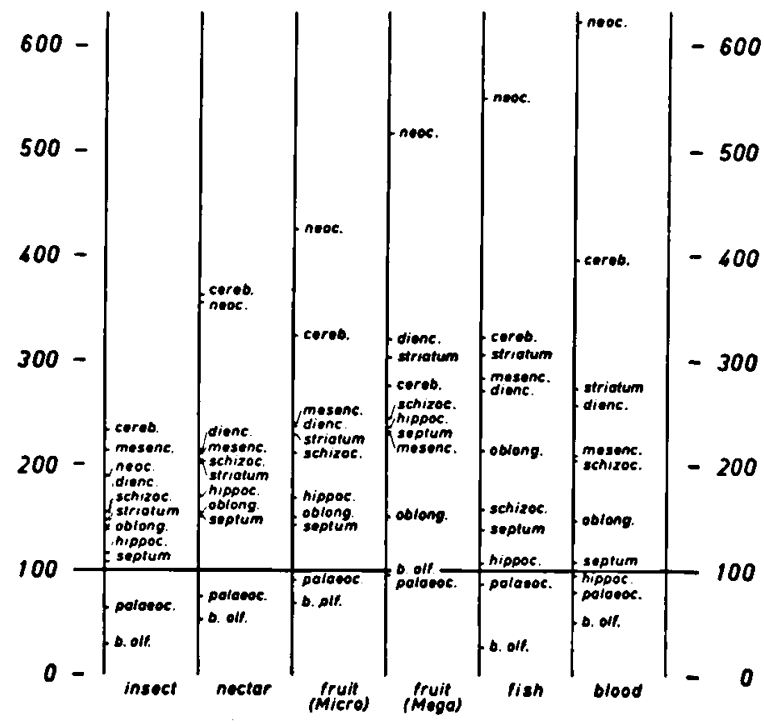

Fig. 4. Average progression indices of the measured brain structures in the various dietary groups. The base of reference is the average progression index of these structures in basal insectivores, which we have inserted as being 100 . For affiliation of the various species to the dietary groups see fig. 2. 
If these assumptions are correct, the results of our analysis can be interpreted as follows: (a) The insectivorous bats are the phylogenetically oldest. They may have evolved from primitive Insectivores essentially through specialization for catching insects on the wing by means of the ultrasonic device. They form a basic group from which all other bats derived. (b) Each progressive evolution of the brain is related to a broadening of the feeding and/or locomotion spectrum and has led to nectar-feeders and frugivorous types on the one hand, carnivorous, fish-eating and blood-sucking types on the other hand (fig. 4). (c) The unilateral dominance of a single sensory system (echolocation) becomes reduced,'a process which can be regarded as "de-specialization". The progressive evolution of higher brain centers, still very small in basal Chiroptera, is thought to be related to that process.

The above interpretation of the results of our measurements is in contradiction with existing conceptions about phylogenetic sequences in Chiroptera, which are commonly based on a unilateral evaluation of the evolutionary process of specialization (i.e. improvement of flying ability) and simultaneously some disregard of the evolutionary process of centralization (development of higher structures in the central nervous system). But as can be shown clearly in bats, the two processes develop almost independently from one another. The existence of centralization (not specialization) is the precondition of progressive evolution. One of the most relevant criteria for centralization or integration in mammals is the size of the neocortex.

The degree of neocorticalization is, however, no yardstick as to the systematic relationship between species. Related forms may be at clearly different levels, whereas very distinct species may be at similar levels (fig. 2). This fact is not specific for bats but known also from other widely ramified groups of mammals (e.g. primates).

On the basis of neocorticalization the question concerning the general evolutionary level of Megachiroptera can be answered: it is high and relatively uniform. In contrast, neocorticalization is distinctly more variable within Microchiroptera.

\section{REFERENCES}

Pirlot, P. \& H. Stephan, 1970. Encephalization in Chiroptera. Can. J. Zool, 48 : 433-444.

Portmann, A., 1947. Etudes sur la cérébralisation chez les Oiseaux, 2. Les indices intra-cérébraux. Alauda, $15: 1-15$.
Stephan, H., 1967. Quantitative Vergleiche zur phylogenetischen Entwicklung des Gehirns der Primaten mit Hilfe von Progressionsindices. Mitt. Max-PlanckGes., 2 : $63-86$. 